\title{
ESTUDO DA ADSORÇÃO E DESSORÇÃO DO CORANTE AZUL REATIVO BF-5G EM CARVÃO ATIVADO DE OSSO
}

\author{
D. S. de CARVALHO ${ }^{1,2}$, C. A. CIONEK ${ }^{1}$, M.A.S.D. de BARROS ${ }^{1}$, P.A. ARROYO ${ }^{1}$ \\ ${ }^{1}$ Universidade Estadual de Maringá, Departamento de Engenharia Química \\ ${ }^{2}$ Universidade Tecnológica Federal do Paraná, Coordenação de Engenharia Têxtil \\ E-mail para contato: carvalho.dayanes@ hotmail.com
}

\begin{abstract}
RESUMO - O objetivo deste trabalho foi avaliar a capacidade de adsorção e dessorção do corante Azul Reativo BF-5G em carvão ativado de osso e analisar o comportamento deste adsorvente em ciclos de adsorção e dessorção em batelada. Os agentes regenerantes utilizados na dessorção foram o álcool etílico e o álcool isopropílico. Notou-se a presença de histerese entre as isotermas de adsorção e dessorção que pode estar associada à irreversibilidade do processo, já que a capacidade de dessorção do corante é pequena. Os ciclos de adsorção e dessorção mostram que adsorção do corante ocorre tanto por interações fortes quanto por interações fracas, sendo que somente o corante adsorvido fracamente na superfície do carvão ativado de osso é capaz de ser dessorvido. Obteve-se também que é possível reutilizar o carvão ativado de osso em ciclos de adsorção/dessorção.
\end{abstract}

\section{INTRODUÇÃO}

O desenvolvimento industrial está diretamente relacionado com a poluição, em que muitas indústrias, tais como as de tintas, têxtil, papel e plástico usam corantes para tingir seus produtos (Crini e Badot, 2008). Dentre essas indústrias, a têxtil merece atenção redobrada devido à elevada quantidade de água utilizada nos processos e, consequentemente, geração de grandes volumes de efluentes líquidos coloridos. Os corante são estáveis sob os efeitos ambientais, como pH, luz e ataque microbiano e, por isso, o uso extensivo destes não só causa um grave problema de saúde pública, mas também sérios problemas ambientais, por causa de sua persistência na natureza e característica não biodegradável (Cisneros et al., 2002 e Li et al., 2011). Dentre os corantes utilizados na indústria têxtil destacam-se os corantes reativos, assim chamados devido à sua capacidade de formar ligações covalentes com a fibra durante o processo de tingimento, apresentando boas características de fixação na fibra e estabilidade química (Kunz et al., 2002).

Muitos métodos são utilizados para remover os corantes de efluentes têxteis, entre eles a adsorção em carvão ativado é encontrada ser superior em comparação com outros métodos de tratamento, em termos de sua capacidade para adsorver eficientemente uma grande variedade de corantes (Tan et al., 2007).

No entanto, as partículas destes adsorventes têm uma capacidade finita para adsorver as moléculas, tornando necessário regenerar o adsorvente ou eliminá-lo. Em certas aplicações, pode ser 


\section{9 a 22 de outubro de 2014 \\ Florianópolis/SC}

econômico descartar o adsorvente após o uso, caso em que pode ser necessário descrevê-lo como uma perda. Na maioria das aplicações a eliminação do adsorvente não é uma opção econômica e, portanto, a regeneração é realizada tanto fora ou no local de adsorção de forma suficiente que o adsorvente possa ser reutilizado (Thomas e Crittenden, 1998).

Dentro deste contexto, o objetivo deste trabalho foi avaliar a capacidade de adsorção e dessorção do corante Azul Reativo BF-5G em carvão ativado de osso e analisar o comportamento deste adsorvente em ciclos de adsorção e dessorção em batelada.

\section{MATERIAIS E MÉTODOS}

\subsection{Materiais}

O carvão ativado de osso utilizado foi doado pela empresa Bonechar Carvão do Brasil LTDA. O diâmetro médio da amostra foi de $0,725 \mathrm{~mm}$. O corante Azul Reativo BF-5G (C.I. Reactive Blue 203MW = 1052) foi fornecido pela Texpal Indústria Química S/A. A Os produtos químico utilizados como agentes regenerantes foram os álcoois etílico e isopropílico. Estes reagentes foram utilizados como obtidos.

\subsection{Cinética De Adsorção}

Para obter a curva cinética de adsorção, os erlenmeyers contendo $20 \mathrm{~mL}$ de solução de corante $(60 \mathrm{mg} / \mathrm{L})$ e $0,2 \mathrm{~g}$ de adsorvente foram adicionados em um banho termostatizado (Nova Ética, modelo $304 \mathrm{DE}$ ) com agitação de $80 \mathrm{rpm}$, por um período total de $24 \mathrm{~h}$. Cada frasco foi retirado do banho em intervalos de tempo pré-determinados e a amostra foi filtrada. A absorbância das soluções de corante, no comprimento de onda predeterminado $(620 \mathrm{~nm}$ para o corante diluído em água e $625 \mathrm{~nm}$ para o corante diluído com os agentes regenerantes) foi determinada por espectrofotômetro UV/vis (Shimadzu, modelo UV-1203). Então a concentração da solução de corante foi calculada lei de BeerLambert e a quantidade de corante adsorvida foi calculada usando a seguinte relação:

$$
q_{t a}=\left[\left(C_{0}-C_{t a}\right) \times V\right] / M
$$

sendo $q_{t a}$ a quantidade de corante removida em qualquer instante $t(\mathrm{mg} / \mathrm{g}), C_{0}$ e $C_{t a}$ são as concentrações de corante na fase líquida inicial e no tempo $t$, respectivamente $(\mathrm{mg} / \mathrm{L}), V$ é o volume da solução de corante (L) e $M$ é a massa da amostra de adsorvente (g). Para representar a cinética de remoção dos corantes no carvão ativado e ajustar os dados experimentais foram utilizados os modelos pseudo-primeira ordem e pseudo-segunda ordem.

\subsection{Equilíbrio De Adsorção}

Para a obtenção da isoterma de adsorção $0,2 \mathrm{~g}$ de adsorvente foram colocados em erlenmeyers contendo $20 \mathrm{~mL}$ de soluções de corante em concentrações que variaram entre 60 a $5000 \mathrm{mg} / \mathrm{L}$. Os erlenmeyers foram colocados em banho termostatizado (Nova Ética, modelo $304 \mathrm{DE}$ ) na velocidade de agitação de $80 \mathrm{rpm}$, a $30^{\circ} \mathrm{C}$, até que o equilíbrio fosse atingido. Ao final do ensaio, as amostras 
foram filtradas e determinaram-se as concentrações das soluções como descrito anteriormente. A quantidade de corante adsorvida no equilíbrio foi calculada utilizando-se a relação:

$$
q_{e a}=\left[\left(C_{0}-C_{e a}\right) \times V\right] / M
$$

sendo que $q_{e a}$ é a quantidade de corante removida no equilíbrio $(\mathrm{mg} / \mathrm{g}), C_{0}$ é a concentração inicial de corante na fase líquida $(\mathrm{mg} / \mathrm{L}), C_{e a}$ a concentração de corante na fase líquida no equilíbrio (mg/L), $V$ o volume da solução (L) e $M$ a massa de carvão ativado de osso (g). Os valores experimentais obtidos foram ajustados pelos modelos de Langmuir, Freundlich e Sips. Além destes ajustes, as isotermas de adsorção também foram classificadas de acordo com Giles et al. (1958).

\subsection{Preparação Do Carvão Ativado Saturado}

Antes de iniciar os ensaios de dessorção foi realizada a saturação do carvão ativado de osso na qual 1,5 g de adsorvente foram adicionados em erlenmeyers contendo $150 \mathrm{~mL}$ de solução de corante com concentração de $4000 \mathrm{mg} / \mathrm{L}$. Todos os erlenmeyers foram agitados em um banho termostatizado (Nova Ética, model $304 \mathrm{DE}$ ) com agitação de $80 \mathrm{rpm}$ e temperatura de $30^{\circ} \mathrm{C}$ por 36 horas para atingir o equilíbrio. Em seguida, a solução foi filtrada e o carvão ativado saturado retido no filtro foi seco em estufa, na temperatura de $40^{\circ} \mathrm{C}$, até massa constante. A concentração da solução foi determinada como descrito anteriormente. A quantidade de corante adsorvida foi determinada utilizando a Equação 2.

\subsection{Cinética De Dessorção}

O ensaio cinético de dessorção foi realizado adicionando-se $0,2 \mathrm{~g}$ de carvão ativado de osso saturado em erlenmeyers contendo $20 \mathrm{~mL}$ da solução de agente regenerante $(50 \% \mathrm{v} / \mathrm{v})$. Estes foram mantidos sob agitação de $80 \mathrm{rpm}$ em um banho termostatizado (Nova Ética, modelo 304 TPA), na temperatura de $30^{\circ} \mathrm{C}$. Cada frasco foi retirado do banho em intervalos de tempo pré-determinados, por um período total de $12 \mathrm{~h}$, e a amostra foi filtrada. A concentração de cada amostra foi determinada como descrito anteriormente e a quantidade dessorvida foi determinada por:

$$
q_{t d s}=\left(C_{t d s} \times V_{r}\right) / M_{S}
$$

sendo que $q_{t d s}$ é a quantidade de corante dessorvida em qualquer instante $t(\mathrm{mg} / \mathrm{g}), C_{t d s}$ é a concentração de corante dessorvido na fase fluida em qualquer instante $t(\mathrm{mg} / \mathrm{L}), V_{r}$ é o volume de solução regenerante (L) e $M_{s}$ é a massa de carvão ativado de osso saturado utilizado (g). Para representar a cinética de remoção dos corantes no carvão ativado e ajustar os dados experimentais foram utilizados os modelos pseudo-primeira ordem e pseudo-segunda ordem apresentado por Katsou et al. (2011).

\subsection{Isoterma De Dessorção}

Para a construção das isotermas de dessorção, $20 \mathrm{~mL}$ de solução de agente regenerante foram adicionados em erlenmeyers contendo massas de carvão ativado de osso saturado que variaram entre 10 a $2000 \mathrm{mg}$. Os erlenmeyers foram colocados em banho termostatizado (Nova Ética, modelo 304 
TPA), com agitação de $80 \mathrm{rpm}$ até que o equilíbrio fosse atingido. As isotermas de dessorção foram determinadas nas temperaturas de 20,30 e $40{ }^{\circ} \mathrm{C}$. Ao final do ensaio, as amostras foram filtradas e as concentrações de equilíbrio foram determinadas como descrito anteriormente. A quantidade de corante dessorvida foi determinada de acordo com:

$$
q_{e d}=\left(C_{e d} \times V_{r}\right) / M_{S}
$$

sendo que $q_{e d}$ é a quantidade de corante dessorvido no equilíbrio, $C_{e d}$ é a concentração de corante dessorvido na fase fluida $(\mathrm{mg} / \mathrm{L}), V_{r}$ é o volume da solução regenerante $(\mathrm{L})$ e $M_{s}$ é a massa de carvão ativado de osso saturado utilizada $(\mathrm{g})$.

A quantidade de corante que ficou adsorvida no carvão foi determinada por:

$$
q_{a d}=q_{e a}-q_{e d}
$$

sendo que $q_{a d}$ a quantidade de corante que ficou adsorvida no carvão após a dessorção (mg/g), $q_{e a}$ é a quantidade adsorvida no carvão virgem $(\mathrm{mg} / \mathrm{g})$ e $q_{e d}$ é a quantidade de corante dessorvida do carvão ativado de osso (mg/g). Como não existe um ajuste específico para isotermas de dessorção, foi utilizada a classificação das isotermas propostas por Giles et al. (1958) para classificar as isotermas de dessorção obtidas

\subsection{Ciclos De Adsorção/dessorção}

A etapa de adsorção foi realizada de acordo com o item 2.4. No caso da dessorção, os ensaios foram realizados de acordo com a melhor condição obtida nas isotermas de dessorção. Desta forma, para o álcool etílico, adicionou-se $0,2 \mathrm{~g}$ de carvão ativado saturado e $20 \mathrm{~mL}$ de solução de álcool etílico $50 \%$ (v/v), em erlenmeyers. Estes foram colocados em um banho termostatizado (Nova Ética, modelo 304 TPA) com agitação de $80 \mathrm{rpm}$ até que o equilíbrio fosse atingido, a $40{ }^{\circ} \mathrm{C}$. Em seguida, a solução foi filtrada e o carvão ativado retido no filtro foi seco em estufa, a temperatura de $40{ }^{\circ} \mathrm{C}$, até massa constante. Após, este carvão foi utilizado para realizar o próximo ciclo de adsorção/dessorção. Para a dessorção com o álcool isopropílico $(50 \%$ v/v) foi utilizado $0,5 \mathrm{~g}$ de carvão ativado. Foram realizados cinco ciclos de adsorção/dessorção para cada um dos agentes regenerantes. A quantidade adsorvida foi calculada pela Equação 2 e a quantidade dessorvida pela Equação 4.

A porcentagem de dessorção foi calculada por:

$$
P_{d}=\left(q_{e d} / q_{e a}\right) \times 100
$$

sendo que $P_{d}$ é a porcentagem de dessorção (\%), $q_{e d}$ é a quantidade dessorvida de corante no equilíbrio $(\mathrm{mg} / \mathrm{g})$ e $q_{e a}$ é a quantidade de corante adsorvido no equilíbrio (mg/g).

\section{RESULTADOS E DISCUSSÃO}

\subsection{Cinética De Adsorção E Dessorção}


A partir da Figura 1 pode-se observar que o tempo necessário para que a solução de corante e o adsorvente entrem em equilíbrio, na etapa de adsorção, é de aproximadamente $18 \mathrm{~h}$. Para a dessorção, tem-se que o tempo de equilíbrio de dessorção foi de aproximadamente 4 horas, mostrando que o processo de dessorção é mais rápido que o de adsorção.
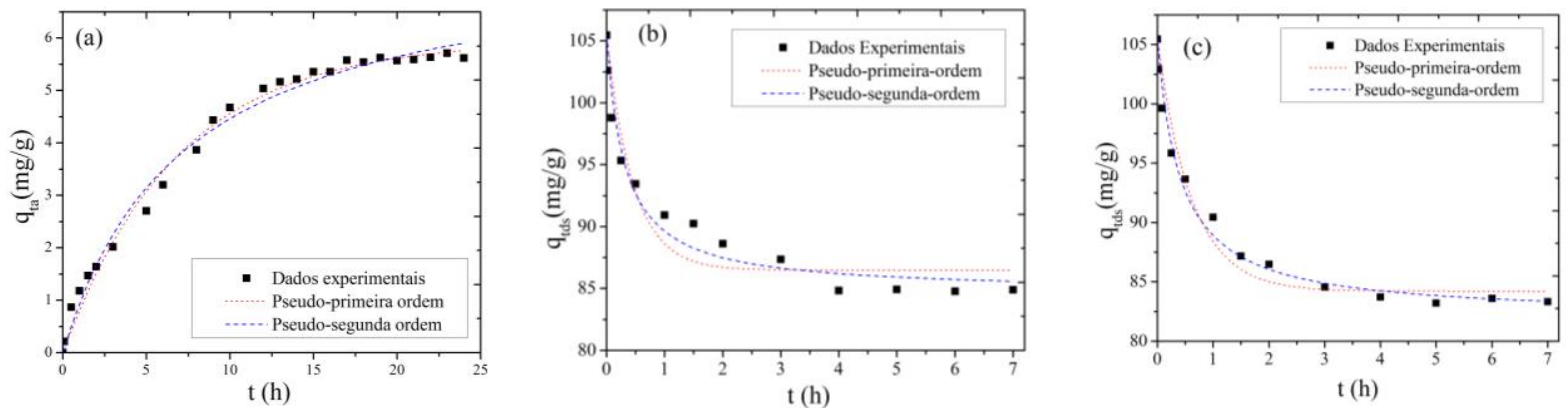

Figura 1 - Curva cinética e ajustes dos modelos cinéticos para a adsorção (a) e dessorção com álcool etílico (b) e álcool isopropílico (c) do corante Azul Reativo BF-5G em carvão ativado de osso, para a temperatura de $30^{\circ} \mathrm{C}$.

Os valores das constantes cinéticas e os coeficientes de correlação $\left(\mathrm{R}^{2}\right)$ obtidos pelo ajustes dos modelos aos dados experimentais, estão listados na Tabela 1. Pode-se observar, para a adsorção, que os modelos cinéticos de primeira e segunda ordem apresentam valores de $\mathrm{R}^{2}$ elevados. Comparando os valores dos modelos tem-se que o valor de $q_{e q}$ obtido utilizando o modelo cinético de pseudoprimeira ordem está mais próximo do valor experimental. Portanto, o modelo de pseudo-primeira ordem é mais adequado do que a equação de pseudo-segunda-primeira ordem para descrever a cinética de adsorção do corante em carvão ativado de osso.

Tabela 1 - Parâmetros da cinética de adsorção do corante em carvão ativado de osso, na temperatura de $30^{\circ} \mathrm{C}$

\begin{tabular}{|c|c|c|c|c|c|c|}
\hline \multirow[t]{2}{*}{ Parâmetros } & \multicolumn{2}{|l|}{ Adsorção } & \multicolumn{2}{|c|}{$\begin{array}{l}\text { Dessorção (Álcool } \\
\text { Etílico) }\end{array}$} & \multicolumn{2}{|c|}{$\begin{array}{l}\text { Dessorção } \\
\text { Isopropílico) }\end{array}$} \\
\hline & $\begin{array}{l}\text { Pseudo- } \\
\text { primeira } \\
\text { ordem }\end{array}$ & $\begin{array}{l}\text { Pseudo- } \\
\text { segunda } \\
\text { ordem }\end{array}$ & $\begin{array}{l}\text { Pseudo- } \\
\text { primeira } \\
\text { ordem }\end{array}$ & $\begin{array}{l}\text { Pseudo- } \\
\text { segunda } \\
\text { ordem }\end{array}$ & $\begin{array}{l}\text { Pseudo- } \\
\text { primeira } \\
\text { ordem }\end{array}$ & $\begin{array}{l}\text { Pseudo- } \\
\text { segunda } \\
\text { ordem }\end{array}$ \\
\hline$q_{e q}(m g / g)$ & $\begin{array}{ll}5,934 & \pm \\
0,1029 & \end{array}$ & $\begin{array}{ll}7,679 & \pm \\
0,2387 & \end{array}$ & $\begin{array}{l}86,49 \\
0,8522\end{array}$ & $\begin{array}{ll}84,71 & \pm \\
0,7589 & \end{array}$ & $\begin{array}{l}84,21 \pm \\
0,6974\end{array}$ & $\begin{array}{ll}82,05 & \pm \\
0,6102 & \end{array}$ \\
\hline$k_{1}\left(h^{-1}\right)$ & $\begin{array}{l}0,1462 \quad \pm \\
0,0080\end{array}$ & - & $\begin{array}{l}2,191 \\
0,4914\end{array} \quad \pm$ & - & $\begin{array}{l}1,630 \quad \pm \\
0,2429\end{array}$ & - \\
\hline$k_{2}(g / m g \cdot h)$ & - & $\begin{array}{l}0,0180 \quad \pm \\
0,0021\end{array}$ & - & $\begin{array}{l}0,1553 \quad \pm \\
0,0357\end{array}$ & - & $\begin{array}{l}0,1032 \\
0,0156\end{array}$ \\
\hline$R^{2}$ & 0,9906 & 0,9888 & 0,9056 & 0,9608 & 0,9571 & 0,9839 \\
\hline
\end{tabular}


Analisando os valores do $\mathrm{R}^{2}$ para a etapa de dessorção pode-se notar que o modelo que melhor se ajusta aos dados experimentais é o modelo de pseudo-segunda ordem, o que pode estar relacionado a pequena quantidade dessorvida de corante, predominando no processo o mecanismo de quimissorção.

\subsection{Isoterma De Adsorção E Dessorção}

As isotermas de adsorção e dessorção obtidas e os respectivos ajustes são mostrados na Figura 2. Pode-se observar o carvão ativado de osso apresentou capacidade de adsorção de aproximadamente $113 \mathrm{mg} / \mathrm{g}$. No caso da dessorção, pode-se verificar que a quantidade de corante dessorvida aumenta com o aumento da temperatura. Logo, a partir das isotermas foi possível obter uma melhor condição para dessorção. No caso do álcool etílico obteve-se uma porcentagem de dessorção de aproximadamente $27 \%$, enquanto que para o álcool isopropílico esta foi de aproximadamente $29 \%$, ambas na temperatura de $40{ }^{\circ} \mathrm{C}$. Estes valores indicam que há uma forte interação do corante com o carvão ativado de osso.
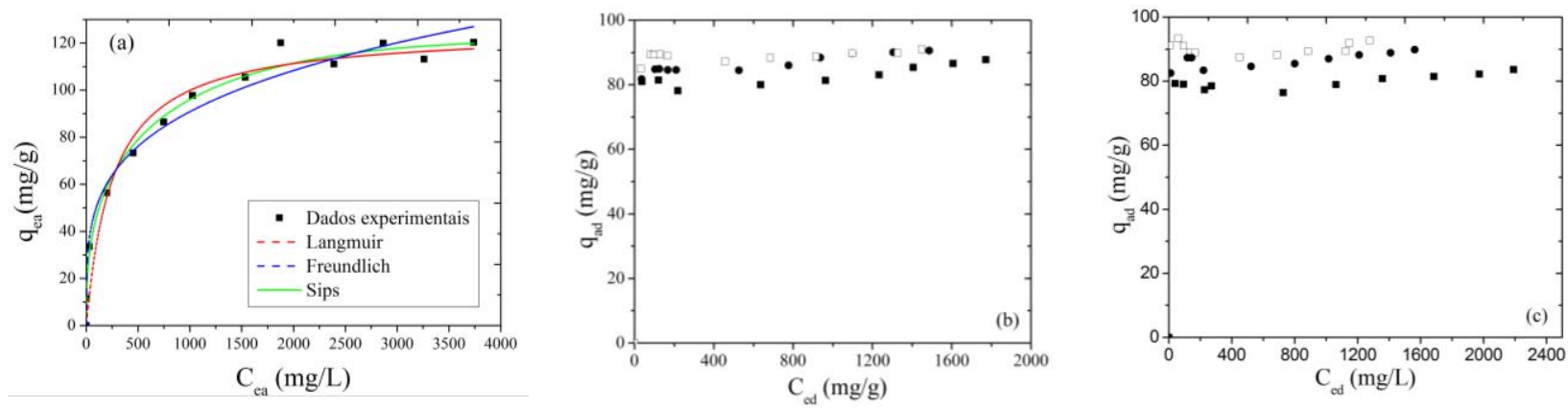

Figura 2 - Ajuste de modelos de isoterma à adsorção (a) e dessorção com álcool etílico (b) e álcool isopropílico (c) do corante Azul Reativo BF-5G em carvão ativado de osso

A Tabela 2 mostra os valores dos parâmetros ajustados pelos modelos de Langmuir, Freundlich e Sips. Analisando os valores de $\mathrm{R}^{2}$ temos que o modelo de Sips é o que melhor se ajusta aos dados experimentais. O fato do modelo de Sips se ajustar melhor aos dados experimentais pode estar relacionada à possibilidade de estarem presentes tanto ligações forte quanto fracas entre o adsorvente e o adsorvato.

Tabela 2 - Parâmetros dos modelos de isoterma de adsorção para o carvão ativado de osso, na temperatura de $30{ }^{\circ} \mathrm{C}$

\begin{tabular}{|l|l|l|l|}
\hline \multicolumn{1}{|c|}{ Parâmetros } & \multicolumn{1}{c|}{ Langmuir } & \multicolumn{1}{c|}{ Freundlich } & \multicolumn{1}{c|}{ Sips } \\
\hline$q_{\max }(\mathrm{mg} / \mathrm{g})$ & $0,4859 \pm 0,0982$ & - & $231,6 \pm 6,821$ \\
\hline$k$ & $0,0038 \pm 0,0009$ & $3,935 \pm 0,3269$ & $1,148 \times 10^{-4} \pm 4,362 \times 10^{-5}$ \\
\hline$n$ & - & $15,69 \pm 2,464$ & $0,35689 \pm 0,03845$ \\
\hline$R^{2}$ & 0,9600 & 0,9778 & 0,9898 \\
\hline
\end{tabular}




\section{9 a 22 de outubro de 2014 \\ Florianópolis/SC}

Por outro lado, a isoterma de adsorção pode ser classificada de acordo com GILES et al. [26], como sendo isotermas do tipo L (L2). Desta forma, a curvatura inicial mostra que quanto mais sítios do adsorvente são preenchidos torna-se cada vez mais difícil para uma molécula de corante encontrar um sítio vazio disponível.

Cabe ressaltar que a inclinação da isoterma de adsorção pode não coincidir com a inclinação da isoterma de dessorção, ou seja, pode haver o aparecimento de uma histerese. Embora não haja uma classificação específica para isotermas de dessorção, a classificação de GILES et al. [26] foi utilizada para demonstrar se as isotermas de adsorção e dessorção em fase líquida possuem diferentes inclinações. Como comentado, a isoterma de adsorção do corante Azul Reativo BF-5G pode ser classificada como sendo do tipo L. Por outro lado, as isotermas de dessorção do corante podem ser classificadas como sendo do tipo $\mathrm{H}(\mathrm{H} 3)$. Esta diferença de comportamento pode estar associada à irreversibilidade do processo, pois existe uma quantidade residual de corante adsorvido no carvão que não pode ser dessorvida, nas condições empregadas.

\subsection{Ciclos De Adsorção/dessorção}

Os resultados obtidos para os ciclos de adsorção/dessorção do corante em carvão ativado de osso são apresentados na Figura 3. Nota-se, no primeiro ciclo de adsorção/dessorção, que a quantidade de corante dessorvido é relativamente baixa em relação à quantidade adsorvida de corante no carvão ativado de osso. Acredita-se que ocorram interações irreversíveis entre as moléculas de corante e o adsorvente, incapacitando que o corante seja completamente removido do carvão ativado, ou seja, o processo de adsorção é irreversível.
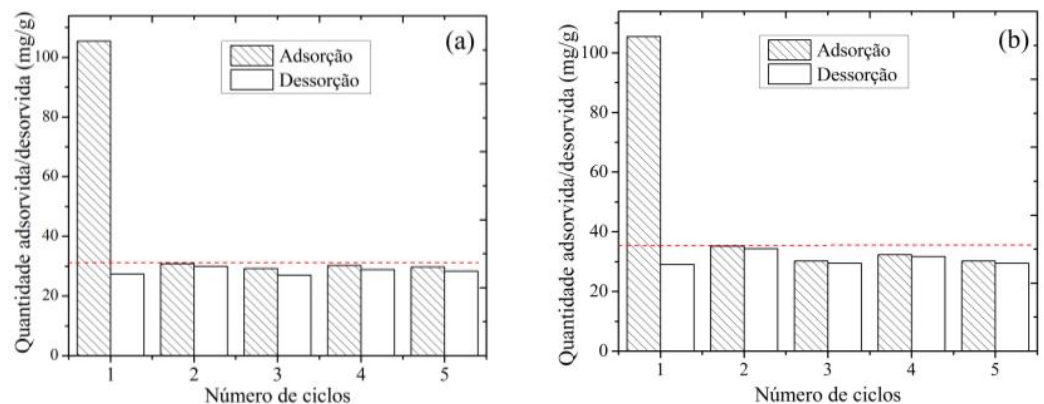

Figura 3 - Ciclos de ( $\square$ ) adsorção e ( $\square$ ) dessorção do corante Azul Reativo BF-5G em carvão ativado de osso para o (a) álcool etílico e (b) álcool isopropílico.

Os resultados obtidos também indicam que pode ocorrer adsorção química e adsorção física, ou seja. Desta forma, o corante ligado ao adsorvente por interações fortes não é capaz de ser dessorvido devido a alterações irreversíveis que ocorrem entre o adsorvato e o adsorvente e somente àquelas moléculas que interagem fracamente foram capazes de serem dessorvidas.

Após a dessorção do primeiro ciclo, a capacidade de adsorção do carvão ativado de osso nos outros ciclos foi em média $28 \%$ para o álcool etílico e $30 \%$ para o álcool isopropílico, em relação à capacidade de adsorção do carvão virgem. A partir do ciclo 2 praticamente toda quantidade de corante adsorvida foi dessorvida, sendo que em média $95 \%$ e $97 \%$ do corante adsorvido foi dessorvido pelo 


\section{9 a 22 de outubro de 2014 \\ Florianópolis/SC}

álcool etílico e pelo álcool isopropílico, respectivamente. Logo, supõe-se que após o primeiro ciclo as moléculas são adsorvidas principalmente por ligações fracas podendo ser quase completamente dessorvidas.

Enfim, observa-se que a partir do ciclo 2 as quantidades adsorvidas e dessorvidas permanecem constantes e, mesmo que a capacidade de adsorção não seja tão alta como a inicial, é possível reutilizar este carvão.

\section{CONCLUSÃO}

De acordo com os resultados obtidos encontrou-se que o processo de dessorção é mais rápido que o de adsorção, porém a quantidade dessorvida é relativamente baixa para os regenerantes estudados, sendo que a eficiência de dessorção é melhorada com o aumento da temperatura. A classificação das isotermas de adsorção e dessorção de acordo com Giles et al., 1958, mostrou o aparecimento de uma histerese, indicando a irreversibilidade do processo. Os ciclos de adsorção e dessorção mostraram que na etapa de adsorção pode ocorrer tanto interações fortes quanto interações fracas, sendo que a partir do segundo ciclo praticamente toda quantidade adsorvida foi capaz de ser dessorvida. Desta forma, acredita-se que é possível reutilizar o carvão ativado de osso no processo de adsorção do corante Azul Reativo BF-5G.

\section{REFERÊNCIAS}

CISNEROS, R.L.; ESPINOZA, A.G.; LITTER, M.I.. Photodegradation of an azo dye of the textile industry. Chemosphere, v. 48, p. 393-399, 2002.

CRINI G.; BADOT, P.M. Application of chitosan, a natural aminopolysaccharide for dye removal from aqueous solutions by adsorption processes using batch studies : A review of recent literature. Prog. Polym. Sci., v. 33, p. 399-447, 2008.

GILES, C.H.; MACEWAN, T.H.; NAKHWA, S.N.; SMITH, D. Studies in Adsorption. Part XI. A system of classifcation of solution adsorption isotherms, and its use in diagnosis of adsorption mechanisms and in measurement of specific surface areas of solids. J. Chem. Soc., v. 786, p. 3973-3992 1958.

KATSOU, E.; MALAMIS, S.; TZANOUDAKI M.; HARALAMBOUS, K.J.; LOIZIDOU, M. Regeneration of natural zeolite polluted by lead and zinc in wastewater treatment systems. J. Hazard. Mater., v. 189, p. 773-786, 2011.

KUNZ, A.; PERALTA-ZAMORA, P.; MORAES, S.G.; DURÁN, N. Novas tendências no tratamento de efluentes têxteis. Quim. Nova, v.25, p. 78-82, 2002.

LI, W.; YUE, Q.; GAO, B.; MA, Z.; LI, Y.; ZHAO, H. Preparation and utilization of sludgebased activated carbon for the adsorption of dyes from aqueous solutions. Chem. Eng. J., v. 171, p. 320-327, 2011.

TAN, I.A.W.; HAMEED, B.H.; AHMAD, A.L.. Equilibrium and kinetic studies on basic dye adsorption by oil palm fibre activated carbon. Chem. Eng. J., v.127, p; 111-119, 2007.

THOMAS, W.J.; CRITTENDEN B. Adsorption Technology and Design. Elsevier Science \& Technology Books, 1998. 